\title{
The Internal Mechanism and Empirical Study on the Change of Development Mode of Green Food Industry Based C-D Product Function
}

\author{
Li Zhao \\ Harbin University of Commerce, Harbin 150028, China \\ Zhaoli0515@163.com
}

Keywords: green food industry; industrial development; C-D production function; industrial development

\begin{abstract}
There exists a close relationship between the mode transformation and the stages of industry development. Based on the analytical model of the mode transformation of industry development, this paper measured the development mode of Chinese green food industry by C-D production function, which revealed the development of Chinese green food industry was characterized by scale expansion pattern, and corresponding policies was put forward to promote the transformation of development mode, the optimization of industrial structure and the development of industry in view of the characteristics of industry stages and industry realistic condition, which provided references for the decision-making of industrial policies and industry planning.
\end{abstract}

\section{Introduction}

Industrial development is not only a process of quantity expansion, but also a process of continuous optimization and upgrading of structure and layout as well as continuous innovation in technology, market, system and management (Malerba Fetal, 2006)[1].The differences in industrial development mode are caused by the differences in constraints, the factors faced by industries at different stages of development, and the constraints on resources and environment. As the relationship between supply and demand and the changes in the pattern of scarce factors require the adjustment of development modes (Zhou Shulian, 2008)[2]. The change of industrial development mode is closely related to the stage of industrial development and also an inherent requirement for the optimization and upgrading of industrial structure. Therefore, it is necessary to clarify the connotation of the development mode of green food industry and its transformation, clarify the inherent rules and influencing factors of the development mode of green food industry, and then make an empirical analysis on the mode of development of the green food industry that is of important theoretical and practical significance to promote the transformation of the mode of green food industry development, the optimization and upgrading of industrial structure and industrial development[3].

The transformation of green food industry in China and its industrial development can not be divorced from the stage of development and industrial base in which the industry is located. In particular, it is necessary to clarify the impact mechanism of the development of green food industry and provide a theoretical basis for the transformation of industrial development through empirical analysis. Therefore, this article mainly solves the following basic questions:(1) Green food industry development mode (change) and its internal relations with the stage of industrial development;(2) Realistic analysis of the transformation of green food Industry development;(3) How to promote the development of green food industry in industrial policy.

\section{The internal mechanism of the transformation of the green food industry development mode}

To study the development of green food industry must relate to the stage of development in 
which the industry is located[4]. Stage of industrial development is the realistic basis and logical starting point for the study of the development of green food industry. The change of green food industry's development mode is determined by its specific stage of development and subjected to the combined effect of various factors in a particular stage of development.

The mode of development of green food industry is the sum of the combination ways, means and modes of various factors that promote the development of green food industry, that is, the source structure, development mechanism and development path of green food industry depends on the way of resource allocation. The problem which development of green food industry solved is the goal to achieve, and the problem which the transformation of green food industry development mode solved is the way to achieve the goal and road, the relationship between them are goals and ways.

The mechanism for the transformation of the green food industry's development mode is that the internal promotion of technological progress and the external stimulus of changes in market consumption demand put forward requirements on the transformation of the development mode of the green food industry in order to promote the transformation of the green food industry's development mode. The transformation of industrial development mode mainly depends on the actual demand of the industrial development stage change, which is the inevitable requirement of the transformation of economic development mode and the scientific development concept. It is also the fundamental way to solve the deep contradictions in industrial economic development and realize the sustainable development of industry. The requirements for the transformation of industrial development mode, which are determined by the specific elements of the development of the green food industry, such as the optimization of resources and elements, the optimization and upgrading of industrial structure, and the improvement of efficiency, are the main factors restricting the transformation of industrial development mode. However, the key to whether the green food industry can change its mode of development lies in whether it provides institutional arrangements conducive to the transformation of the industrial development mode, that is, the support of government industrial policies and the guidance and catalytic role played by them[5]. These factors directly contribute to the green food industry The improvement of development ability and the optimization and upgrading of industrial structure and industrial development. At the same time, the optimization and upgrading of the green food industry structure is an inherent requirement and an outward manifestation of the industrial development mode transformation.

The transformation of green food industrial development mode should take into account the stage of industrial development, and the constraints of resource conditions and the existing industrial base and the changes of market demand and consumption upgrade determined by the government. Through the government industrial policy and institutional arrangements, enlarge the green food industry. By coordinating the relationship between technology, market and policy, we can seek the best fit point for the development variables of green food industry, and promote the optimization of green food industry structure and efficiency, so as to realize the sustainable development of industry and the enhancement of industrial competitiveness.

\section{Determination of the development mode of green food industry}

In this paper, we use the improved C-D production function and Solow residual model to determine the development mode of green food industry to judge the main driving factors and industrial growth mode of industrial development, and provide theoretical support for the transformation of green food industry development mode in order to promote green food industrial resource optimization and industrial development.

\subsection{Model setting and variable selection}

Assuming that the technological progress is Hicks neutrality, adopting Cobb Douglas production function model which Dobbin improved is used to observe the effect of capital and labor factors on industrial development. Select the output value of green food industry as output variables, capital, labor, land and technology as input variables, and establish the contribution rate model of 
production function and growth factor of green food industry as follows:

$$
Y_{t}=A_{t} K_{t}^{\alpha} L_{t}^{\beta} M_{t}^{\gamma} e^{r t}
$$

Among them, the variable $Y_{t}$ represents the total output value of green food industry (100 million yuan), $A_{t}$ represents the impact of technological progress on industrial growth, namely total factor productivity, $\boldsymbol{K}_{t}$ represents the total amount of fixed capital and liquidity in the green food industry(100 million yuan), $\boldsymbol{L}_{t}$ represents the labor force in the green food industry(10,000), and $\boldsymbol{M}_{t}$ represents the monitoring area $(10,000 \mathrm{mu})$ in the green food industry. $\alpha, \beta, \gamma$ represent the output elasticity of capital, labor and land respectively. $r$ is the annual average rate of technological progress, indicating the average annual rate of increase in output due to the comprehensive technological progress. The contribution rate of total factor productivity growth is the "Solo residual value" of output growth rate other than labor and capital (Schultz, 1968), which contains more extensive than just technological progress, such as the improvement of labor quality, Factor optimization, management improvement and institutional change (Helpman, 1990).

\subsection{Empirical process and result analysis}

The development of green food industry is affected by natural environment, social and economic environment and policy intervention, but the most basic production factors are land, labor force and capital. Due to the limitation of data availability, this paper uses the input and output data of relevant factors of green food industry in Heilongjiang Province (2003-2013) to make empirical research. The data are from 《Statistical Yearbook of Heilongjiang Province》 from 2003 to 2014 and 《Statistical Report of Green Food》 of Heilongjiang Green Food Development Center.

First of all, the model is initially estimated and tested. Assuming there is technological progress, the progress of technological progress is linear over time. Using Eviews6.0 to eliminate the dimension of the above sample data OLS method to estimate the parameters, the preliminary estimation results and the main parameters shown in Table 1.

TABLE I. The preliminary estimation results of green food industry production function

\begin{tabular}{ccccc}
\hline variable & $\begin{array}{c}\text { Parameter } \\
\text { estimation }\end{array}$ & $\begin{array}{c}\text { Standard } \\
\text { deviation }\end{array}$ & t- Statistics & P- value \\
\hline Constant term C & $\ln \mathrm{A}=-11.63$ & 6.7059 & -1.736 & 0.1576 \\
capital lnK & $\alpha=0.879$ & 0.488 & 1.8 & 0.1461 \\
Labor force $\operatorname{lnL}$ & $\beta=1.367$ & 0.734 & 1.86 & 0.1362 \\
$\begin{array}{c}\text { Monitoring area } \\
\text { lnM }\end{array}$ & $\gamma=1.408$ & 1.238 & 1.1369 & 0.3191 \\
Time t & $\mathrm{r}=-0.475$ & 0.339 & -1.4025 & 0.2334 \\
\hline \multicolumn{5}{c}{$\mathrm{R} 2=0.981 \quad \mathrm{~F}=51.81$ D.W.=1.676 } \\
\hline
\end{tabular}

From the above estimation results, it can be seen that the model has a large coefficient of determination ( $\left.\boldsymbol{R}^{2}=\mathbf{0 . 9 8 1}\right), \boldsymbol{F}$ test $(F=51.81$, Prob $(F-$ statistic $)=0.001)$ is significant. But in the $\mathrm{t}$ test, the coefficient of $\mathrm{t}$ value did not pass the test. But in the $t$ test, the coefficient of $t$ value did not pass the test. The $t$-test value of the parameter estimate of the constant term and the capital is too small to pass the significance test. After adjusting the model and re-estimating and testing, the results show that the statistical properties have been greatly improved compared with the preliminary estimation results. The explanatory power of the model is strong, and there is no significant autocorrelation problem among the variables. Therefore, we get the production function model of green food industry:

$$
\begin{array}{r}
\operatorname{Ln}\left(\hat{Y}_{t}\right)=2.62+0.132 \operatorname{Ln}\left(K_{t}\right)+0.414 \operatorname{Ln}\left(L_{t}\right)+0.308 \operatorname{Ln}\left(M_{t}\right)+0.1056 \operatorname{Ln}(t) \\
(0.1028)(0.1627)
\end{array}
$$




$$
R^{2}=0.945 \quad \text { D.W. }=1.78 \quad F=46.96
$$

The final production function of the green food industry is:

$$
\hat{Y}_{t}=13.96 K_{t}^{0.132} L_{t}^{0.414} M_{t}^{0.308} e^{0.1056}
$$

Through the green food industry production function estimation and testing, you can get the following analysis results:

1) For each factor input, the output elasticity of capital, output elasticity of labor and output elasticity of monitoring area of green food industry in Heilongjiang Province are 0.132, 0.414 and 0.308 respectively. We can see that the high contribution rate of labor and monitoring area to output is the main factor to promote the growth of green food industry. The promotion of technological progress on the green food industry is not obvious. Therefore, how to increase the contribution rate of technological progress to the production of green food industry in Heilongjiang Province will be an important issue for a long time.

2) Because $\alpha+\beta+\gamma \prec 1$, indicating that the overall green food industry is currently in the stage of economic diseconomies of scale, characterized by extensive industrial development, the overall economy of scale has not been played. It also shows that there is little scope for increasing output by increasing input, and the growth efficiency of the development of the epitaxial industries is not high.

\section{Conclusion}

Through the above theoretical analysis and empirical research, draw the following conclusions:

1) The mode of development of the green food industry is restricted by the stage of economic development and has stable mutual adaptability and interdependence with a certain level of productivity, economic development strategy and economic system. It also reflects the specific economic development momentum structure and economic growth objectives.

2) Due to the inherent promotion of technological progress and the external pull of market and industry demand, it is a realistic requirement to promote the optimization of green food industry structure and the transformation of industrial development mode.

3) The sources and determinants of the economic growth of green food industry are mainly explained by the growth of investment in production factors, which shows that the mode of economic growth of green food industry is an extensive and modest development mode driven by factors. Therefore, on the basis of large-scale development of the green food industry, it is necessary to make adjustments to the industrial structure and transform the mode of industrial growth and further develop the structure and efficiency.

\section{Acknowledgment}

This research was supported by Philosophy and Social Sciences Planning Project in Heilongjiang (No.16JYB14); Humanities and Social Sciences Planning Project of Heilongjiang Education Department (No.12542060); and Ph.D. research project of Harbin Universe of Commerce (No. 14RW14).

\section{References}

[1] Malerba F, Cantner U. Innovation, industrial dynamics and structural transformation: Schumpeterian legacies[J]. Journal of Evolution-arv Economics, 2006: 34-58.

[2] Zhou Shulian. How to understand and realize the transformation of economic development mode [J]. Theory Frontiers, 2008 (6): 5-9

[3] Zheng Yuxin.Measurement of Total Factor Productivity and "Phased Laws" of Economic Growth Patterns [J]. Economic Research. 
[4] John Adams. Industrial clusters and regional economic development in China: the case of "green "food[J]. Journal of Chinese Entrepreneurship, 2009, 1(3): 279-294.

[5] Xue Bai. The mechanism and measurement of transformation of economic growth mode [J]. Management Science2009,22(5):112-114 